\title{
Endodontically Compromised Tooth and Associated Unusual Oral Habit: Foreign Object Entrapped in Tooth
}

\author{
Singh $\mathbf{G}^{1}$, Banda $\mathrm{NR}^{2 *}$, Kandya $\mathrm{A}^{3}$ and Verma $\mathrm{P}^{4}$ \\ ${ }^{1}$ Private Practitioner, Gwalior, India \\ ${ }^{2}$ Department of Dentistry, Ibn Sina National Medical \\ College, Saudi Arabia \\ ${ }^{3}$ Private Practitioner, Indore, India \\ 4Private Practitioner, J abalpur, India \\ *Correspondling author: Banda Naveen Reddy, \\ Department of Dentistry, Ibn Sina National Medical \\ College, J eddah, Saudi Arabia
}

Received: April 28, 2018; Accepted: May 16, 2018; Published: J une 12, 2018

\begin{abstract}
Encountering foreign bodies in the oral cavity is not new; these foreign bodies may be left in the oral cavity as a result of traumatic injury or iatrogenically. A detailed history, and proper clinical and radiographic examinations are then essential to verify about the nature, size, location of the foreign body, and the difficulty involved for its retrieval. This situation more commonly arises in children as they have the habit of placing foreign objects in the mouth in order to alleviate their discomfort, which might get stuck inside the teeth, and are adamant to confess the same to their parents due to fear. These foreign objects may act as a potential source of infection and may later lead to a painful condition. This paper discusses a similar situation about the presence of an unusual foreign object within broken upper incisor and its management.
\end{abstract}

Keywords: Foreign body; Endodontic treatment; Paediatric patient; Oral habit

\section{Introduction}

Various kinds of self imposed injuries in the hard and soft tissues of the oral cavity have been reported in the literature, which may have traumatic, iatrogenic or accidental causes [1]. These injuries may vary from simple nail/lip biting to a more severe form of trauma. Finding a foreign body inside a tooth is a special situation which is not a frequent encounter and in often diagnosed as a part of routine clinical or radiographic check-up, as the tooth often remains asymptomatic. Also, the patients are generally hesitant to reveal because of the fear from their parents [2-4].

These conditions are more commonly seen in children having an open pulp chamber due to trauma, caries or while undergoing root canal therapy. According to the literature, objects found inside the teeth may include pencil leads [2], stapler pins [5], incense sticks [6], safety pins [7], thorns etc. The embedment of these foreign objects may further complicate the situation by acting as a nidus of infection leading to pain and swelling (most commonly), recurrent abscess or may be haemorrhage. A case of actinomyosis of maxillary central incisor has also been reported due to the same reason [8].

This situation holds the need to retrieve the embedded objects from the root canal which in itself is quite challenging for the clinician but even more importantly for a pedodontist as they are dealing with a developing root canal [9]. The objects if located superficially in the pulp chamber can be retrieved in a relatively easier and faster manner; however, if the object has been lodged inside the root canal may complicate the situation further hampering the cleaning and shaping of the root canal and might even need a retrograde surgical removal, depending upon the size/shape of the object and diameter, curvature and accessibility of the root canal [4]. There is however, no standard protocol set for these kinds of procedure and different techniques and procedures have been used and reported in the literature till date [10].

\section{Case Presentation}

A 13-year-old boy was referred to the Department of Paediatric Dentistry, Modern Dental College and Research centre, Indore with the chief complaint of pain in maxillary permanent central incisors since 2 weeks. On examination, the patient had a Class I Angle's molar relationship bilaterally. The right maxillary central incisor was discoloured and broken down (Ellis class IV tooth fracture [11]). Radiographic examination showed that the apices of both the incisors were closed. Periapical radiograph of tooth [11] showed a radioopaque object within the root canal (Figure 1). Another periapical radiograph was then taken (SLOB technique to confirm the location of the object) from a slightly different horizontal angle, using parallax, and it was confirmed that the metallic object was located within the root canal rather than in the periodontal ligament space. On further questioning, the patient admitted to 'insert some object' few months previously.

The tooth 11 was then isolated and a conventional access cavity was prepared. A thin, tapering, diamond fissure bur on an air rotor hand piece was used to slightly widen the orifice to facilitate access to instrumentation. An ultrasonic scaler was used to clear the debris from root canal orifice and also to facilitate loosening of the metal object. Root canal was irrigated with $5.2 \%$ sodium hypochlorite solution. A no. $20 \mathrm{H}$ file was used to bypass and engage the foreign body (Figure 2). After a series of attempts, the object was moved coronally and pulled out with a mosquito forceps (Figure 3,4). The canal was then irrigated with normal saline, which helped to remove the debris. Working length was established (Figure 5) and proper biomechanical preparation was done using step-back technique. Calcium hydroxide was used as the intracanal medicament. In the next appointment, obturation of the tooth was done with guttapercha using lateral condensation technique (Figure 6). The final restoration was done with the metal ceramic crown. The tooth 21 was 


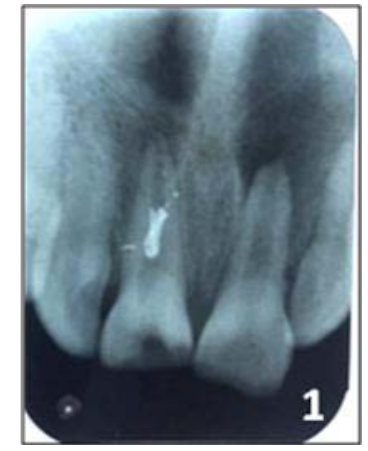

Figure 1: Showing radio opaque object within root canal of traumatized tooth.

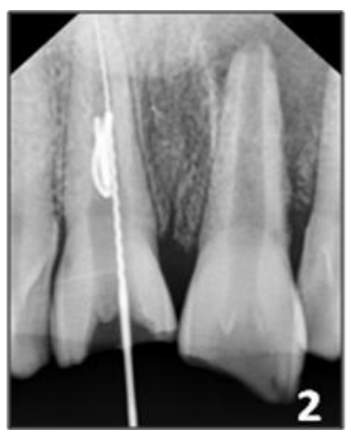

Figure 2: File bypassed and engaged with object.

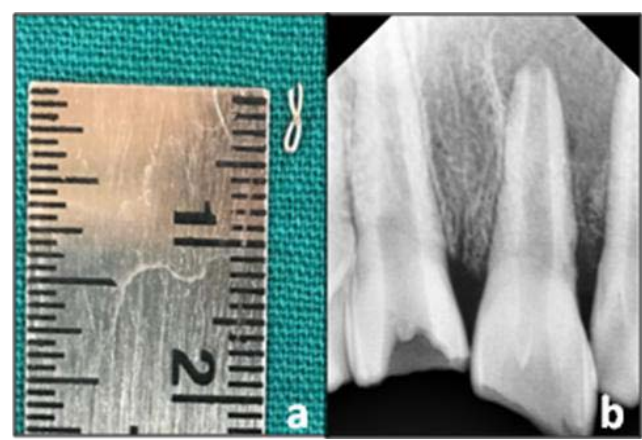

Figure 3(A,B): Foreign object removed from root canal.

also restored aesthetically using composite.

\section{Discussion}

Children are more in a habit of placing foreign objects in the oral cavity. These foreign bodies inside teeth are diagnosed accidentally on clinical or radiographic examination of teeth, more so in children with open/traumatic tooth, who are encountered with the habit of placing objects in it so as to overcome any kind of discomfort. This might then lead to infection, pain, swelling, and recurrent abscess formation as a sequel to the pulpal exposure and lodgement of the foreign body.

Zillich and Pickens [12] and Turner [7] cited cases wherein hat pins and dressmaker pins that were used to remove the food plugs from the root canals of maxillary and mandibular incisors undergoing endodontic treatment had eventually fractured inside the root canals of these teeth. Gelfman [13] and colleagues reported a

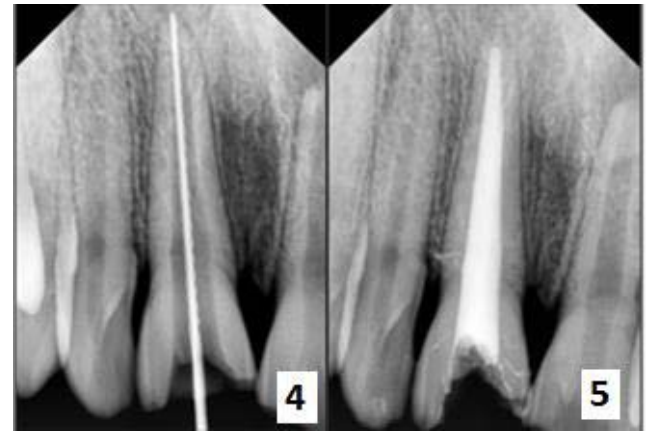

Figure 4 and 5: Working length and obturation is done.

case where in a 3-year-old child had inserted two straws into the root canal of a primary central incisor, which were later extracted. Harris [14] reported the placement of varied objects within the root canals of maxillary anterior teeth. These included pins, wooden toothpick, a pencil tip, plastic objects, toothbrush bristles and crayons. The patients had inserted these objects in the root canal to remove food plugs from the teeth. Placements of beads, a paper clip and a stapler pin in the root canals of maxillary incisors have also been reported. Lamster and Barenie [15] reported insertion of a conical metallic object in the distal root of the primary left first molar.

Basically, the foreign objects lodged in root canal can be classified into metallic and non-metallic objects. Because of their radioopaque nature, the metallic objects can be readily identified from routine radiographs. McAuliffe [3] suggested variable radiographic techniques like parallax views, vertex occlusal views, different triangulation techniques, and tomography in order to locate the radio-opaque foreign objects. Specialized radiographic techniques such as radiovisiography and 3D computerized axial tomography (3D CAT) scans can aid in the localization. Microscopy and ultrasonic tips can be used as auxiliary tools. Those objects which are not metallic are very difficult to be identified on radiographs as they are radiolucent. Such objects are also a prominent cause of endodontic failure when they are pushed beyond the apex and this may also end up in recurrent periapical abscess. Hence, upon encountering resistance in a canal that was left open for a long period of time either after trauma or during endodontic treatment, it is recommended to take proper history and do careful instrumentation to prevent apical pushing of the object.

Foreign bodies in the soft tissues of the oral cavity have also been reported. A habit such as nail-biting, lip biting etc does not immediately predict the presence of oral soft tissue foreign bodies, but one that repeatedly introduces foreign bodies into the oral cavity is a concern and makes history taking and examination critically important [16] also since the children are often unaware of their nailbiting habit or are reluctant to admit it.

A conventional practice employed during emergency root canal treatment involves leaving the pulp chamber open where pus continues to discharge through the canal and cannot be dried within a reasonable period of time. Weine [17] in 2004, suggested to make the patient wait in the dental clinic for about an hour (or even more) to let the tooth drain completely and finally send the patient after sealing the access cavity once the draining stops. Now, since the 
access opening is sealed, no new microorganism scan enter and also the food lodgement into the tooth can be shunned [18].

In order to remove the foreign objects which lie in the pulp chamber or root canal with the use of ultrasonic instruments [19], the Masserannkit [20], modified Castroveijo needle holders [21] have been used. Ethylene-diamine-tetraacetic acid (EDTA) has been suggested as a useful aid in lubricating the canal when attempting to remove any foreign object. The Steglitz forceps have also been described for use of removal of silver points from the root canal. There is a description of an assembly of a disposable injection needle and thin steel wire loop formed by passing the wire through the needle being used. This assembly was used along with a mosquito haemostat to tighten the loop around the object [4]. Nehme [22] suggested using the microscope in addition to the ultrasonic filing so as to eradicate the metallic obstructions inside the canal. Srivastava and Vineeta [23] suggested that if needed, periapical surgery or even intentional reimplantation may also be done for such cases.

\section{Conclusion}

Many children with a habit of placing various objects in the oral cavity eventually end up as a foreign body lodgement into the pulp chamber or root canal leading to pain and infection. Parental negligence is responsible to a great extent in such kind of accident as they fail to keep watch on their children and their teeth. So a detailed case history including oral habits and clinical and radiographic examination should be carried out before proceeding with diagnosis and treatment planning, because a hidden oral habit can lead to obstruction in proper treatment line.

\section{References}

1. Blanton PL, Hurt WC, Largent MD. Oral factitious injuries. J Periodontol. 1977; 48: 33-37.

2. Hall JB. Endodontics--patient performed. ASDC J Dent Child. 1969; 36: 213216.

3. Macauliffe N, Drage NA, Hunter B. Staple diet: a foreign body in a tooth. Int J Paediatr Dent. 2005; 15: 468-471.

4. Roig-Greene JL. The retrieval of foreign objects from root canals: A simple aid. J Endod. 1983; 9: 394-397.

5. Chand K, Joseph S, Varughese JM, Nair MG, Prasanth S. Endodontic management of an unusual foreign body in a maxillary central incisor. J Conserv Dent. 2013; 16: 474-476.
6. Gadgil RM. Foreign incense. Br Dent J. 2009; 207: 305

7. Turner $\mathrm{CH}$. An unusual foreign body. Oral Surg Oral Med Oral Pathol 1983 56: 226.

8. Costa F, Robiony M, Toro C, Sembronio S, Politi M. Endoscopically assisted procedure for removal of a foreign body from the maxillary sinus and contemporary endodontic surgical treatment of the tooth. Head Face Med. 2006; 2: 37.

9. Prabhakar AR, Namineni S, Subhadra HN. Foreign body in the apicalportion of a root canal in a tooth with an immature apex: A case report. Int Endod J. 2008; 41: 920-927.

10. Hulsmann M. Methods for removing metal obstructions from the root canal. Endod Dent Traumatol 1993; 9: 223-237.

11. Enrique Basrani. Fractures of the teeth. 4th edition, Lea \&Febiger, Elsivier Mosby, 1982.

12. Zillich RM, Pickens TN. Patient-included blockage of the root canal: Report of a case. Oral Surg Oral Med Oral Pathol. 1982; 54: 689-690.

13. Gelfman WE, Cheris LJ, Williams AC. Self attempted endodontics: A case report. ASDC J Dent Child. 1969; 36: 283-284.

14. Harris WE. Foreign bodies in root canals: Report of two cases. J Am Dent Assoc 1972; 85: 906-911.

15. Lamster IB, Barenie JT. Foreign objects in the root canal: Review of literature and report of 2 cases. Oral Surg Oral Med Oral Pathol. 1977; 44: 483-486.

16. Pinky C, Ravi KS, Krishna A, Vanka A. Fingernails- foreign objects in root canal: a case report J Clin Exp Dent. 2011; 3: e386-9.

17. Weine FS. Endodontic therapy. 6 th ed. Elsivier, Mosby, 2004

18. Nair PN. On the causes of persistent apical periodontitis: A review. Int Endod J. 2006; 39: 249-281.

19. Meidinger DL, Kabes BJ. Foreign object removal utilizing the caviendo ultrasonic instrument. J Endod. 1985; 11: 301-304.

20. Williams VD, Bjourndal AM. The Masseran technique for the removal of fractured posts in endodontically treated teeth. J Prosthet Dent. 1983; 49: 46-48.

21. Fros UG, Berg JO. A method for the removal of broken endodontic instruments from the root canals. J Endod. 1983; 9: 156-159.

22. Nehme WB. Elimination of intracanal metallic obstruction by abrasion using an operational microscope and ultrasonics. J Endod. 2001; 27: 365-367.

23. Srivastava N, Vineeta N. Foreign body in the periradicular area. J Endod 2001; 27: 593-594
Austin J Dent - Volume 5 Issue 5 - 2018

ISSN : 2381-9189 | www.austinpublishinggroup.com

Banda et al. (C) All rights are reserved
Citation: Singh G, Banda NR, Kandya A and Verma P. Endodontically Compromised Tooth and Associated Unusual Oral Habit: Foreign Object Entrapped in Tooth. Austin J Dent. 2018; 5(5): 1116. 